\title{
Signos culturais em projetos de espaços efêmeros
}

\section{Cultural signs in projects of ephemeral spaces}

Santos Lima da Cunha, Alessandra; Graduada; Instituto Federal de Educação Ciência e Tecnologia da Paraíba alesantosw@gmail.com

Xavier da Costa, Roberta; Mestre; Instituto Federal de

Educação Ciência e Tecnologia da Paraíba

robertaxavierdacosta@gmail.com

\section{Resumo}

Este artigo realiza uma descrição acerca dos signos culturais presentes nos projetos dos espaços efêmeros, tendo como objeto de estudo o hall de entrada do Salão de Artesanato da Paraíba, com intuito de propor construtos para um método de análise. Para a realização desta pesquisa foram levados em consideração fatores culturais e semióticos, com o intuito de identificar a representação da identidade paraibana de cada elemento visual. Este, por sua vez, é analisado segundo as categorias de referências culturais dos signos. O estudo, de natureza teórica, têm como etapas metodológicas o levantamento de dados bibliográficos, a pesquisa de campo e documental e a análise dos elementos visuais abordados. Com os resultados obtidos, identificou-se a presença de quatro componentes semióticos, ícones e símbolos, na 21 e edição do Salão de Artesanato da Paraíba que estão relacionados à cultura paraibana, constituindo uma narrativa de identidade cultural para o espaço.

Palavras Chave: signos; cultura; identidade; e espaços efêmeros.

\section{Abstract}

This article presents a description of cultural signs presented in the projects of ephemeral spaces, having as object of study the entrance hall of the Paraiba's Handcraft Fair, with the purpose of proposing constructs for a method of analysis. For the realization of this research were considerated the cultural and semiotics factors, in order to identify the representation of the Paraiba's identity of each visual element. This one, in turn, it's analized according to the categories of cultural references of the signs. The study, of a theoretical nature, have as methodological steps the collection of bibliographic data, the field and documentary research and the analysis of visual elements approached. With the results obtained, it was possible to identify four semiotic components, icons and symbols, in the $21^{\circ}$ version of the Paraiba's Handcraft Fair which are related to the Paraiba's culture, composing a narrative to the cultural identity of the space.

Keywords: signs; culture; identity; and ephemeral spaces. 


\section{Introdução}

No âmbito do design, a identidade cultural é essencial no processo de agregação de valores culturais ao produto, seja este um objeto de uso, um ambiente ou um sistema de informação. Esses valores são agregados em forma de simbologias, ou signos, que tornam o produto indenitário e representativo desses valores. É através do ato de projetar que o designer planeja a forma que a identidade estará presente no produto, relacionando-o com os aspectos sociais e culturais específicos de cada cliente. Estas particularidades são traduzidas por meio de signos que são concretizados em um objeto e o diferencia dos demais presentes no mercado. Para tanto, muitas vezes, o projetista utiliza como linguagem e expressão a ferramenta dos elementos visuais da semiótica ${ }^{1}$.

A relação simbólica entre a identidade e o design de interiores se torna ainda mais estreita quando concerne o planejamento de espaços efêmeros ${ }^{2}$. De caráter transitório, porém não menos instigantes, os projetos de espaços efêmeros requerem do projetista uma ambientação impactante e que expresse a identidade do cliente ao seu público consumidor de forma direta. Considerandose que esses espaços têm períodos determinados para exposição, a afinidade com o público alvo é essencial. Assim sendo, para criar a sincronia, o profissional que concebe o espaço deve usar os recursos que remetam nesse público a mensagem simbólica, através de elementos que associam os signos à cultura que está sendo representado naquele espaço.

No projeto de design de interiores, a comunicação visual é essencial no processo de expressão da identidade do cliente. É através dos elementos visuais que compõem o espaço que a ideia do projeto é concretizada. No anseio de aprofundar os estudos acerca de utilização de signos e símbolos culturais, assim como estudar sobre projetos em espaços efêmeros, esta pesquisa se propôs a realizar a identificação e descrição dos signos, com base no artesanato, da cultura paraibana. Para tal, teve-se como objeto de estudo o hall das versões 21 , 230 e 25 으 do Salão de Artesanato da Paraíba (SAP), sendo a primeira versão citada a que apresentou maior destaque e da qual será abordado o resultado no decorrer deste trabalho. O SAP trata-se de um evento organizado pelo Programa de Artesanato da Paraíba (PAP) que busca promover a divulgação e a comercialização dos produtos artesanais do Estado da Paraíba.

No contexto da relação entre os signos representativos da cultura paraibana e o projeto de espaços efêmeros, ainda se fazem pouco conhecidas as metodologias que abordam a aplicação de signos culturais no planejamento de espaços internos. A limitação de conhecimento sobre a temática gera uma lacuna no desenvolvimento de projetos de design interiores que sejam representativos da identidade do cliente. Deste modo, tem-se como problemática o seguinte questionamento: De que forma os signos da cultura paraibana se manifestam no projeto do hall de entrada da 21을 edição do Salão de Artesanato da Paraíba?

\footnotetext{
${ }^{1}$ Conforme Santaella (1983), o termo semiótica tem origem do grego semeion, que significa signo. Assim, compreendese que a semiótica é a ciência que estuda os signos e suas linguagens.

2 Espaços efêmeros, de acordo com Nishikawa (2016), compreende um conceito projetual de estruturas temporárias, associadas às edificações de caráter transitório, comumente chamadas de design e/ou arquitetura de espaços efêmeros.
} 


\section{Desenvolvimento}

\subsection{Cultura paraibana: artesanato como representação da identidade cultural de um povo}

O significado de cultura pode ser compreendido como um conjunto de características, habilidades, valores artísticos e espirituais presentes em uma determinada sociedade, pode-se afirmar que ela é resultado da relação entre o homem e o meio em que vive. Segundo Borba (2006), a cultura é formada por diversos elementos, como: a origem do povo, os componentes etnológicos, a história, a arte, as tradições, as crenças e os modos de agir e pensar que constituem uma sociedade específica. Assim sendo, a cultura é o fruto do processo de vivência do homem perante a sociedade, alinhando características a um grupo específico.

A cultura popular, por sua vez, utiliza como referência de sua manifestação cultural a produção de um povo, como a linguagem, os escritos, a criatividade e a oralidade, ressaltando o conhecimento que é passado de geração para geração. Deste modo, a cultura popular surge da adaptação do homem com o meio em que vive, englobando as diversas áreas do conhecimento, tais como: artesanato, folclore, crenças, hábitos, ideias, linguagem, moral, artes, tradições e costumes. (SOUZA; PEREIRA, 2014).

Diante disto, apreende-se que tudo aquilo que engloba os fazeres e saberes populares, assim como a herança histórica e cultural de um povo, em um determinado espaço geográfico é classificado como produção da cultura popular. Para os fins do desenvolvimento da pesquisa, tendo em vista que o objeto de estudo desta pesquisa é um salão de artesanato, é de suma importância situar o papel do artesanato no contexto cultural e representativo da identidade paraibana.

O artesanato está diretamente relacionado ao processo histórico do homem e, em especial, à necessidade de criar utensílios para serem utilizados no cotidiano. Algumas pessoas compreendem o fazer artesanal como uma manifestação artística, enquanto outras o enxergam como uma atividade produtiva e de rendimento econômico. Independentemente de qual vertente é a correta, é válido afirmar que os elementos artesanais correspondem a uma produção cultural e representam a capacidade criativa de uma determinada região ou comunidade. (MARTINS, 2017, p. 220)

Os produtos artesanais são dotados de grande valor simbólico e cultural, uma vez que são feitos com base na vivência individual de cada artesão, dos recursos naturais disponíveis na região em que são produzidos e das influências do meio. Estes valores agregados ao artesanato são responsáveis pelo destaque destes itens no mercado, considerando-se que o consumidor reconhece o produto e o associa a uma cultura específica. Assim, pode-se alegar que o artesanato é um elemento que afirma a identidade cultural, uma vez que este representa uma realidade cultural local da região em que é produzido e, consequentemente, exprime as especificidades de um determinado povo.

Ademais, outro importante fator a se destacar sobre o artesanato compreende a observação dos aspectos históricos, geográficos e culturais, os quais são essenciais para a compreensão do artesanato como manifestação cultural. Tendo em vista que as peças feitas pelos artesãos e as técnicas empregadas podem, por exemplo, variar de acordo com a região e a matéria prima mais abundante no local. 


\subsection{Espaços efêmeros}

O termo efêmero tem origem da palavra grega ephémeros, que representa uma condição caracterizada por um estado passageiro e que dura pouco tempo. De acordo com Carnide (2012, p.21), a obra efêmera anuncia uma criação com tempo de vida determinado, isto é, a duração ocorre de forma transitória e prevê sua própria destruição. Devido a sua essência momentânea, o espaço efêmero busca causar o maior impacto possível com os materiais disponíveis para a sua execução.

Deste modo, tem-se que o principal objetivo da estrutura efêmera é transmitir sua mensagem ao público alvo com o maior impacto visual e com a menor quantidade de matéria e energia utilizada. Tendo em vista que no espaço efêmero a experiência não será repetida, a instalação deve, portanto, atingir sua finalidade na primeira tentativa de comunicação com o público.

Neste tipo de espaço, há um conjunto de elementos que são essenciais para seu planejamento e execução exitosas, como: o tempo, a luz, o som e a narrativa. Outros fatores também são responsáveis por fundamentar o caráter efêmero, sendo estes: a leveza, a facilidade de montagem, a economia de recursos e a eficiência em produzir uma resposta às transformações de maneira ágil, além da aptidão em conceber ambientes e atmosferas. (NISHIKAWA, 2016)

As áreas de atuação referentes aos espaços efêmeros são variadas, desde pequenos ambientes teatrais a grandes eventos. Segundo Rossi (2015), "o design de espaços provisórios pode estar presente em cenários para espetáculos e eventos culturais, em produções expográficas de museus, em projetos de intervenções urbanas e em stands comerciais em shoppings e feiras".

A respeito do presente trabalho, considerou-se o hall do Salão de Artesanato da Paraíba como um espaço efêmero expográfico e cenográfico, tendo em vista que ele é tanto utilizado para expor obras, quanto para criar um cenário que apresente uma narrativa relacionada à cultura do artesanato paraibano.

\subsubsection{Design de espaços expográficos e cenográficos}

O termo expografia tem origem do latim exponere, que significa "pôr para fora", isto é, exibir. A exposição tem como objetivo disseminar um conhecimento, propagar uma mensagem do transmissor (objeto exibido) para o receptor (visitante). O intermédio entre a instituição cultural e o público é o espaço expositivo, que tem como função comunicar ao público; logo, sua forma de apresentação do conteúdo interfere na comunicação. Assim, o êxito de uma exposição está diretamente relacionada com a qualidade tridimensional do espaço expositivo, pois exerce relevante papel no processo comunicativo, tornando este espaço o próprio cenário da exposição. (GONÇALVES, 2004; SATURNINO, 2014).

Segundo Mantovani (1989), a cenografia é compreendida como uma composição em um espaço tridimensional, o lugar teatral. Para esta composição, faz-se necessário a utilização de elementos como cor, luz, forma, volume e linhas; além da introdução de peso, tensões, equilíbrio ou desequilíbrio, movimento e contraste no conjunto como um todo.

A separação entre a cena e o espaço do espectador desaparece na exposição e o visitante pode ser entendido como um ator, no sentido de que, percorrendo o circuito da mostra, é um ser ativo (um corpo presente e fundamental) no seu dispositivo. O seu percurso, a deambulação, é essencial. (GONÇALVES, 2004) Deste modo, compreende-se que a cenografia desempenha um importante papel na elaboração do desenho para a recepção estética da exposição no desenho 
museográfico desta, construindo uma maior imersão do visitante no conteúdo que está sendo exibido no ambiente.

Para o desenvolvimento da presente pesquisa, considerou-se a cenografia como parte integrante e compositiva do espaço de exposição, conforme os preceitos supracitados presentes na obra de Gonçalves (2004) e de acordo com a definição de Mantovani (1989), a qual afirma a cenografia como ato criativo que possui a intenção de organizar visualmente o lugar teatral para que possa ocorrer a relação entre a cena e o público.

No projeto expográfico, vários recursos podem ser utilizados de modo a transmitir a mensagem, isto é, comunicar-se com o público visitante, dentre eles: textos, legendas, ilustrações, fotografias, cenários, mobiliário, sons, texturas, cheiros e temperatura. Estes elementos podem estar presentes no espaço expositivo e influenciam diretamente na percepção do visitante em relação ao conteúdo exposto, podendo, sobretudo, fazer com o que o indivíduo reviva lembranças e associe com experiências anteriores. (CURY, 2005)

Logo, pode-se concluir que o planejamento do projeto expográfico está diretamente relacionado com o êxito do processo de interação entre o espaço e o público, assim como também influencia o processo de comunicação entre estes.

Assim sendo, a compreensão do conteúdo sobre espaços expográfico e cenográficos constitui um importante requisito para a análise dos objetos de estudo do presente trabalho, tendo em vista que o hall de entrada do Salão de Artesanato da Paraíba é considerado um espaço efêmero cenográfico e expositivo. As informações abordadas anteriormente, tais como: conceituação e importância de cenografia e expografia; elementos de composição especial (cor, luz, forma, volumes, linhas, entre outros); fases do projeto expográfico (planejamento e ideias, design, elaboração técnica, montagem e manutenção); recursos de transmissão da mensagem (textos, legendas, ilustrações, fotografias, sons, entre outros); e organização espacial são utilizadas como parâmetros para compreensão e análise do objeto de estudo, de modo a identificar como o espaço foi projetado, qual a função, o objetivo e a mensagem a ser transmitida.

\subsection{Semiótica: signos aplicados no design}

\subsubsection{Introdução à semiótica}

O termo semiótica tem origem da palavra grega semeion, que quer dizer signo. Portanto, considera-se que esta área do conhecimento é responsável por estudar os signos e as formas de construção do sentido sem se tratar exclusivamente da linguagem falada ou escrita. A importância da semiótica está relacionada ao fato de possibilitar uma análise representativa de objetos, processos e fenômenos nos diversos campos do saber. (SANTAELLA, 1983; NIEMEYER, 2015)

De acordo com Santaella (1983, p.7), essa análise pode ocorrer por meio de vários elementos visuais como formas, cores, texturas, linhas e tantos outros elementos visuais presentes nos elementos de comunicação visual que circundam o ser humano diariamente. Deste modo, pode-se assimilar que a importância da semiótica consiste na descrição e investigação de elementos de todos os campos de linguagem, a fim de identificar os aspectos simbólicos e representativos que cada objeto ou processo traz consigo. Logo, no processo de comunicação, torna-se possível identificar o significado das coisas através do fenômeno de semiose, no qual um determinado componente assume a função de signo, isto é, faz referência a um objeto ausente.

A semiótica, como ciência que investiga acerca do processo de construção dos significados, 
leva em consideração três principais componentes: o signo, denominado de representamen; o objeto, que é aquilo ao qual o signo se refere; e o interpretante, que corresponde a compreensão de algo na medida em que é evocado pelo signo. (MORRIS, 1976)

\subsubsection{Signos}

Os sistemas de linguagem, os quais compõe o embasamento da comunicação, são constituídos por códigos. Estes, por sua vez, são organizações de signos que dão a construção de um sentido. Segundo a definição de Niemeyer (2016), um signo é algo que representa uma determinada coisa para um indivíduo em um contexto específico, estando relacionado a uma experiência anterior com o objeto remetido.

Eco (1997, p.21) afirma que o signo é utilizado para indicar e transmitir uma mensagem sobre algo para alguém e está inserido em processos de transmissão de informação de qualquer categoria. Por conseguinte, pode-se apreender que o signo não corresponde unicamente a um significado ou referência de algo, mas sim a um elemento complexo que atua na transmissão da mensagem e, consequentemente, faz parte do processo de comunicação como um todo.

Baseando-se na segunda tricotomia dos signos estabelecida por Peirce (1990, p.52), o signo pode ser denominado de ícone, índice ou símbolo. Para Peirce (1990, p.52), “um Ícone é um signo que se refere ao Objeto que denota apenas em virtude de seus caracteres próprios, caracteres que ele igualmente possui quer um tal Objeto exista ou não. É certo que, a menos que realmente exista um tal Objeto, o Ícone não atua como signo (...)". Por conseguinte, apreende-se que o ícone é um signo que faz referência direta ao objeto ao qual se refere por meio de suas características semelhantes. Já sobre o símbolo, segundo o referido autor, pode-se afirmar que a "fundamentação da relação com seu objeto é uma relação imputada".

Para esta pesquisa, buscou-se destacar as naturezas de classificação do objeto para compreensão de dois conceitos essenciais: o ícone e o símbolo, os quais serão identificados projeto. A ausência da análise de índices se deu por convenção, tendo em vista que na referida edição do objeto de estudo não apresenta elementos visuais que estão ligados a um determinado objeto por meio proximidade/semelhança e não representação.

\subsubsection{Signos culturais aplicados ao design}

Segundo Eco (1997), o signo é um elemento utilizado no processo de comunicação e significação. Assim como os elementos visuais, os signos podem representar linguagens não verbais, como a gestual, a visual, a sonora e a simbólica. Além de assumir um importante papel no processo de criação e expressão de uma identidade cultural, especialmente no âmbito do design. (GRILLI, 2015).

No design, o signo pode ser utilizado como principal meio de materializar e concretizar a identidade de um grupo específico no projeto. Ao trazer para um mobiliário ou ambiente símbolos representativos de uma cultura, o projetista está realizando um processo de agregação de valor ao produto, tornando-o original, pois difere dos demais oferecidos no mercado. Segundo Grilli (2015), os profissionais de design têm cada vez mais procurado assimilar o impacto causado pelos elementos culturais presentes em um produto e a sua relação com o usuário, de modo a criar valores simbólicos que resgatem a identidade cultural perdida durante o processo de globalização.

Pode-se considerar, pois, o design como uma ferramenta estratégica na valorização do patrimônio material e imaterial, assim como na criação dos signos culturais. Tendo em vista que é 
durante o processo de projeto que são inseridos estes elementos simbólicos representativos de uma identidade cultural. No contexto do design, destaca-se pelo menos três razões principais para acrescentar os signos culturais no projeto, sendo elas: criar/afirmar uma identidade brasileira nos produtos; valorizar o produto nacional diante da disputa de mercado; e garantir a originalidade dos produtos brasileiros. (NIEMEYER, 2015)

É possível afirmar ainda que a identidade do projeto, assim como sua mensagem simbólica, assume grande importância no processo de agregação de valor ao produto. É através de características específicas, que comuniquem a cultura e o território a qual pertence, que o objeto é notado diante da grande diversidade de produtos disponíveis no mercado. Assim, o design constitui um instrumento essencial na prática de agregar valor ao produto, de modo a possibilitar maior destaque ao mesmo.

Mediante o exposto, apreende-se que o produto não é comprado apenas por sua função prática, isto é, pelas características de uso e manuseio do objeto, mas sim pelas funções simbólicas e estéticas. Isto ocorre devido à maneira como os valores são agregados ao produto, criando um forte apelo emocional com o consumidor, que passa a se identificar com a mercadoria em questão. Em consonância com este pensamento, Bürdek (2006) conta que "(...) a vivência positiva de um produto pode, por exemplo, fazer com que a relação preço-demanda seja anulada. Com outras palavras: quando o valor agregado ("added value") pelo design é muito grande, o produto é comprado apenas por ele e não por sua função prática."

Nos dizeres de Niemeyer (2015), quão maior for o nível de informação do produto, mais forte será sua identidade. Esta, por sua vez, pode ser analisada segundo três tipos de informação: sobre a existência, quando o produto estabelece sua própria condição fenomênica; sobre a origem, no qual o produto informa sobre seu designer, fabricante, país e cultura; e de acordo com sua qualidade, onde o produto informa sua função ou uso.

Ainda sobre as referências sígnicas expressas na identidade do produto, pode-se interpretála sob três tipos de referência: as referências icônicas, as referências indiciais e as referências simbólicas. (NIEMEYER, 2015) Para o desenvolvimento deste estudo, será abordado apenas as referências icônicas e simbólicas, restringindo-se à análise de referências apenas associadas a categoria do signo.

As referências icônicas dizem respeito aos aspectos de semelhança do objeto e ao seu signo, seja por meio de imagem, seja por meio de metáfora ou até mesmo pela estrutura. Nesta categoria, a aparência pode, pois, ser analisada conforme a tradição da forma, a semelhança cromática, a semelhança material, a metáfora, o estilo e a semelhança de ambiente. (NIEMEYER, 2015)

Já as referências simbólicas estão associadas aos símbolos, que, por sua vez, são estabelecidos culturalmente para então serem difundidos e aplicados. A esta categoria estão associados os aspectos de símbolos gráficos, cor simbólica, forma simbólica, posições e posturas simbólicas e material simbólico. (NIEMEYER, 2015).

Mediante o exposto, e com base na obra de Niemeyer (2015), a presente pesquisa realiza uma análise do objeto de estudo a nível da origem da identidade do produto, pois é nesta categoria que será possível analisar as características culturais, isto é, os signos, presentes na identidade do objeto de estudo. É levado em consideração, ainda sobre a obra da referida autora, algumas das características de manifestações da identidade, como elementos de configuração, materiais 
aplicados, composição e organização das partes e esquema cromático.

\section{Metodologia}

O método utilizado para desenvolvimento de uma identificação de construtos para análise dos espaços em estudo nesta pesquisa possui duas bases principais. A primeira corresponde à análise cultural dos signos proposta por Grilli (2015) e, a segunda, à classificação semiótica, que utiliza como parâmetro as características de manifestação da identidade de produto, propostas na obra de Niemeyer (2016). A análise da objeto de estudo utilizou como base as referências no produto exposto pela autora, identificando uma relação cultural dos signos presentes no projeto do hall do Salão de Artesanato da Paraíba com a cultura paraibana.

Niemeyer (2016) afirma que os signos apresentam relação cultural e, portanto, os objetos aos quais eles fazem referência devem ser considerados elementos culturais. Partindo deste ponto de vista, a análise desenvolvida realizou, inicialmente, a classificação do signo identificado no espaço. Em seguida, foi informado se o signo classificava-se em ícone ou símbolo. Uma vez classificado o signo, ele é analisado segundo os aspectos de referência, podendo ser referências icônicas, simbólicas ou indiciais. Contudo, para o desenvolvimento desta pesquisa - a nível de graduação -, restringiu-se a análise apenas das referências relacionadas a categoria do signo.

As referências icônicas levam em consideração os aspectos de semelhança entre o signo e o objeto e para o desenvolvimento deste trabalho foram adotados os seguintes elementos como categorias para análise do signo: a tradição da forma, a semelhança cromática, a semelhança de material, o estilo e a semelhança de ambiente. Já em relação as referências simbólicas, considerouse os aspectos de: símbolos gráficos, cor simbólica, forma simbólica e material simbólico. Uma vez realizada a identificação das referências dos signos, estes foram analisados conforme o contexto da cultural local.

\section{Resultados}

No hall de entrada da 21 o edição do Salão de Artesanato (Fig. 1), identificou-se quatro principais signos culturais, sendo eles: o vestuário, a flor em crochê, a bandeirinha de São João e a luminária.

Figura 1 - Hall de entrada do 21으 Salão de Artesanato da Paraíba.

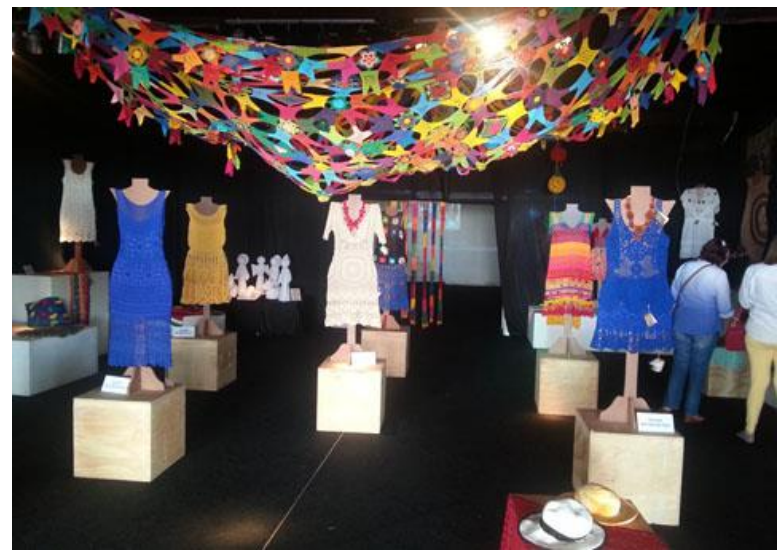

Fonte: Governo do Estado da Paraíba. (2015) 
O primeiro, correspondente ao vestuário (Fig. 2), pode ser classificado como símbolo, uma vez que faz referência a um convenção pré-estabelecida, na qual o crochê relaciona-se com o artesanato paraibano. Este símbolo, por sua vez, só pode ser reconhecido por aqueles indivíduos que tiveram uma experiência anterior com a cultura paraibana ou tem conhecimento a respeito da mesma. As peças de roupas, feitas de crochê, renda e tecelagem estão diretamente relacionados a cultura da Paraíba, uma vez que se encontram inseridos na tipologia de fios do artesanato paraibano. Para a análise deste signo, tomam-se como parâmetros de referências simbólicas as seguintes características: cor simbólica e material simbólico.

Figura 2 - Vestido em crochê.

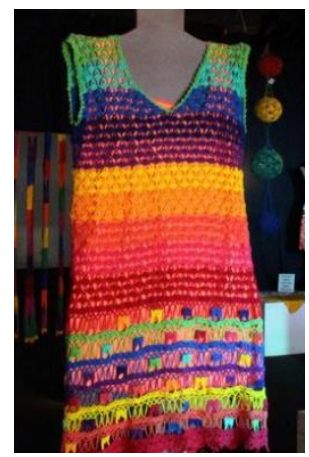

Fonte: Programa de Artesanato da Paraíba (2015)
Figura 3 - Trajes de quadrilha junina.

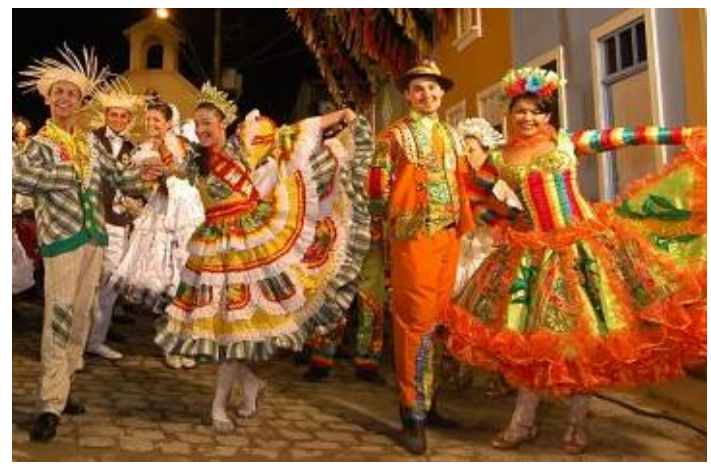

Fonte: Paraibadebate.com.br (2016)

Em relação a cor simbólica, identifica-se no vestuário uma grande quantidade de cores distintas, que simbolizam a diversidade cultural presente tanto nas comemorações populares como o tradicional São João -, quanto nos trajes folclóricos - das quadrilhas juninas e do bumba meu boi. Há também peças em tons mais claros, beges, na qual foram empregados os fios do algodão colorido.

No que concerne o material simbólico, a matéria prima dos fios, geralmente de algodão, empregada na confecção das peças de roupa remetem de imediato a técnica empregada na elaboração do vestuário. $O$ fio do algodão é associado à própria técnica do crochê e das rendas em geral, as quais constituem uma importante tipologia do artesanato paraibano, podendo ser apreendido este significado por aqueles que tiveram algum contato com esta cultura. Deste modo, pode-se apreender que o material utilizado no vestuário é associado à técnica utilizada para o fabrico deste. 
Figura 4 - Associação do material à técnica do crochê.

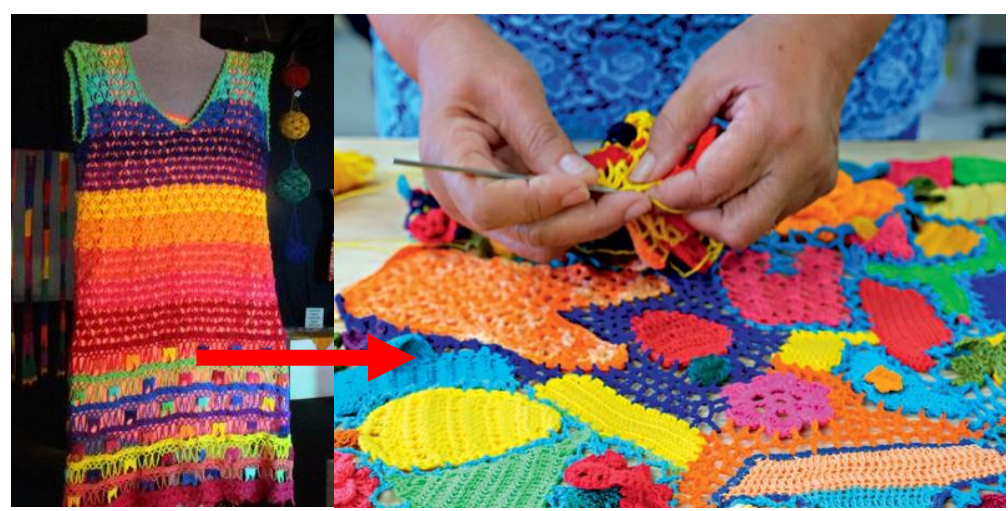

Fonte: Autoria própria (2017)

Já a flor de crochê (Fig. 5) classifica-se como ícone, devido à característica de semelhança entre o signo e seu objeto representado. Nos municípios do interior da Paraíba, on de a renda e o crochê constituem uma forte tradição cultural, o formato de flor é o elemento básico e primário aprendido por quem inicia o aprendizado da técnica do crochê e representa uma das flores típicas dos semiáridos e sertões nordestinos, a flor do umbu. Deste modo, para a análise do referido signo, identificou-se as seguintes referências icônicas: tradição da forma e semelhança cromática.

Figura 5 - Signo da flor de crochê.

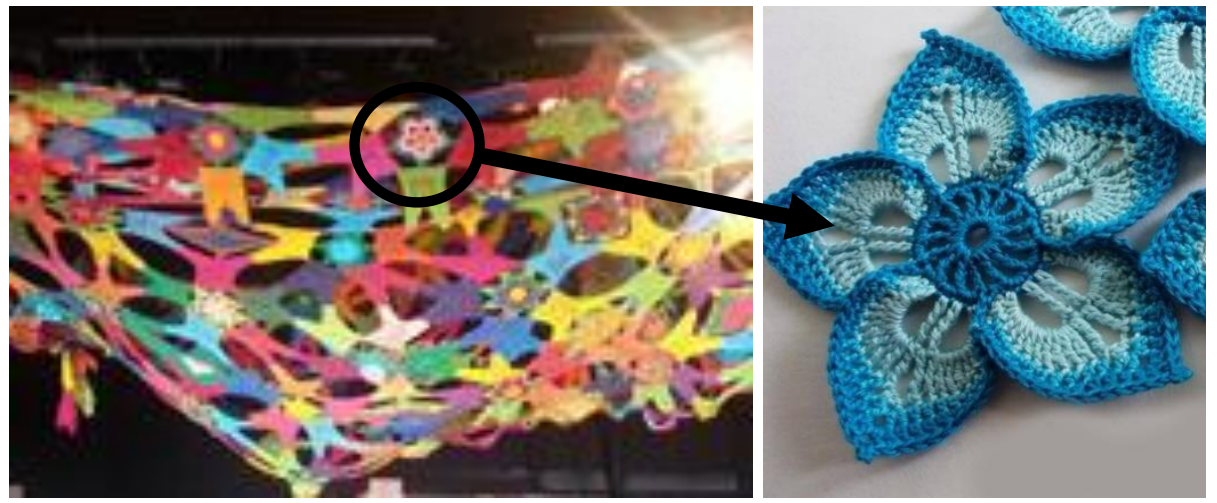

Fonte: Autoria própria (2017)

A tradição da forma está relacionada com a semelhança entre o signo e seu objeto representado. Pode-se afirmar que a flor de crochê apresenta características formais muito semelhantes a de seu objeto, sendo identificada especialmente por este atributo. As Fig. 6 e Fig. 7 representam a similaridade das formas. 
Figura 6 - Flor do umbu.

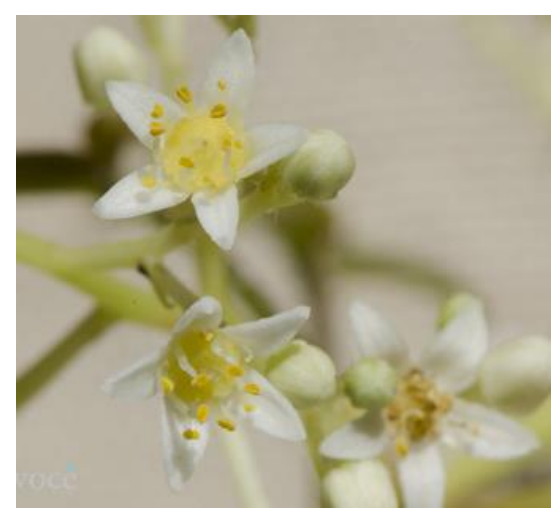

Fonte: Focadoemvoce.com (2015)
Figura 7 - Tradição da forma do signo da flor de crochê.

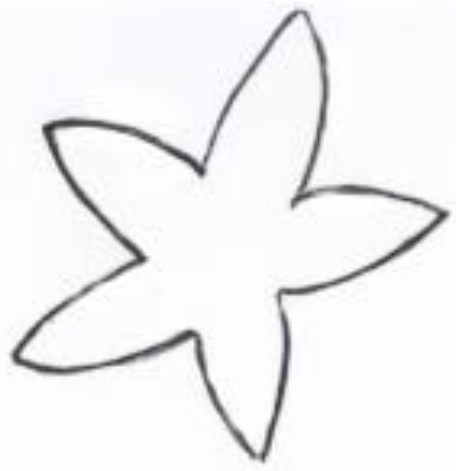

Fonte: Autoria própria (2017)

A semelhança cromática de um ícone ocorre pelo uso de cores similares, que contribuem para a associação do sentido entre o signo e o objeto. Na flor de crochê, as cores utilizadas neste são análogas e fazem referência às cores vibrantes que, assim como o vestuário, estão presentes nas comemorações populares da festa São João, no carnaval e nas danças populares, como o bumba meu boi e a quadrilha junina.

Figura 8 - Semelhança cromática com bumba meu boi.
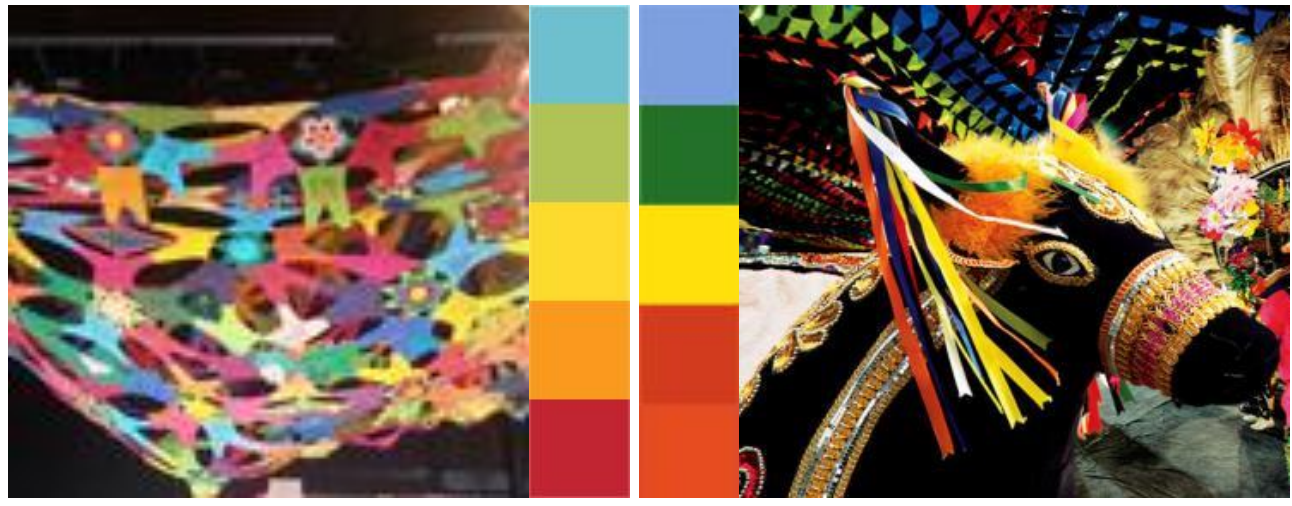

Fonte: Autoria própria (2017).

O terceiro signo, a bandeirinha de São João (Fig. 9), classifica-se como ícone, uma vez que a associação deste signo para com seu objeto representado se dá por semelhança de forma e cores, tornando-se assim um elemento que faz alusão direta ao produto. Na bandeirinha, duas categorias de referências icônicas foram encontradas, sendo elas: a tradição da forma e a semelhança cromática. 
Figura 9 - Detalhe do signo da bandeirinha de São João no hall de entrada

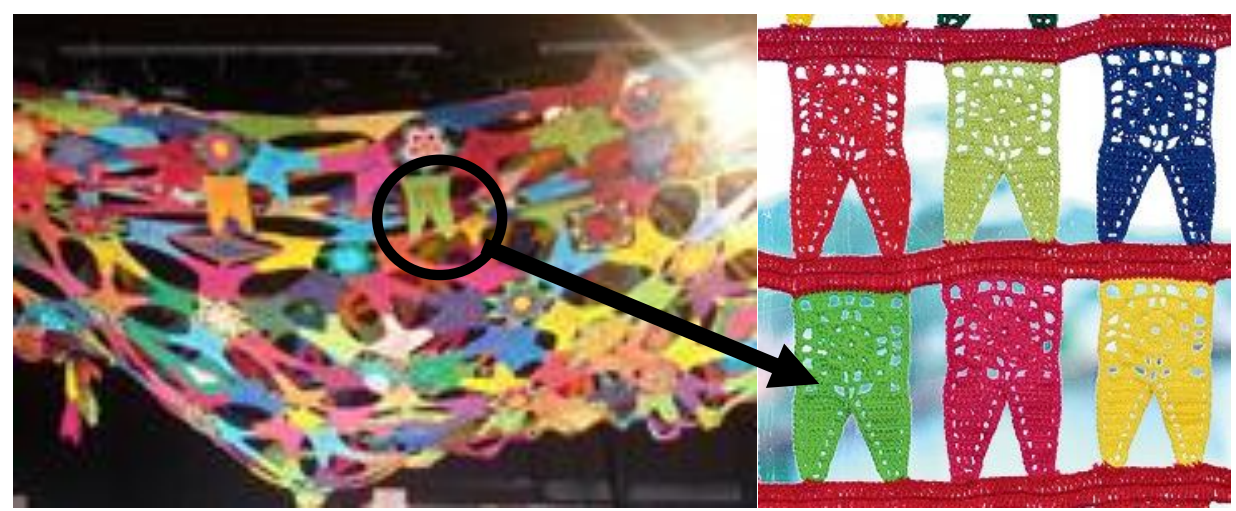

Fonte: Autoria própria (2017).

A respeito da tradição da forma, ao analisar a bandeirinha de crochê, associa-se rapidamente ao formato das bandeirinhas que enfeitam as festas de São João, conforme ilustra as Fig. 11 e Fig. 12. Esta festa compreende uma celebração à colheita, especialmente do milho, e à fartura. Unindo amigos e familiares, a festa de São João é rica em diversidade de cores e texturas, expressando a diversidade e a alegria do povo brasileiro. A bandeirinha, enfeite típico deste evento, é considerada como um signo desta celebração e, consequentemente, da cultura popular nordestina, sendo a cidade de Campina Grande, na Paraíba, conhecida por abrigar o maior São João do mundo.

Figura 10 - Bandeirinhas de São João.

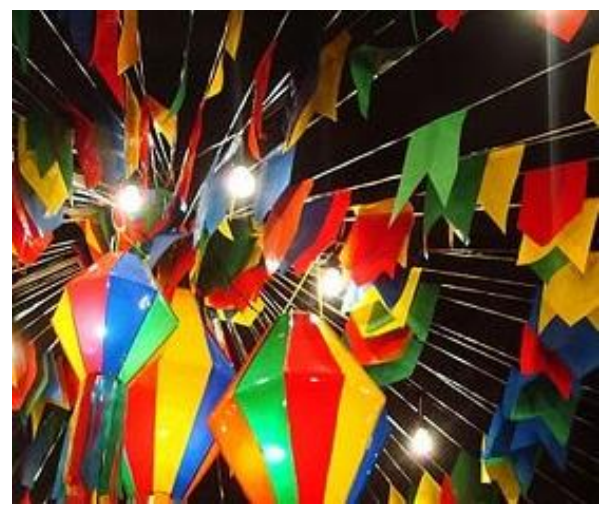

Fonte: Porsimas.blogspot.com.br (2013)
Figura 11 - Aspecto formal da bandeirinha de São João.

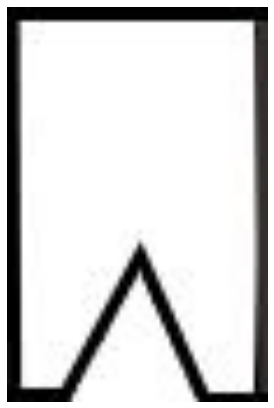

Fonte: Autoria própria (2017).

Em consideração aos aspectos de semelhança cromática, as cores presentes na referida festa popular estão presentes no signo da bandeirinha feita de crochê pelos artesãos paraibanos. A similaridade das cores utilizadas, demonstrada na Fig. 13, está relacionada a uma representação da diversidade e da alegria do povo nordestino. Estas características, portanto, também fazem parte da cultura paraibana. 


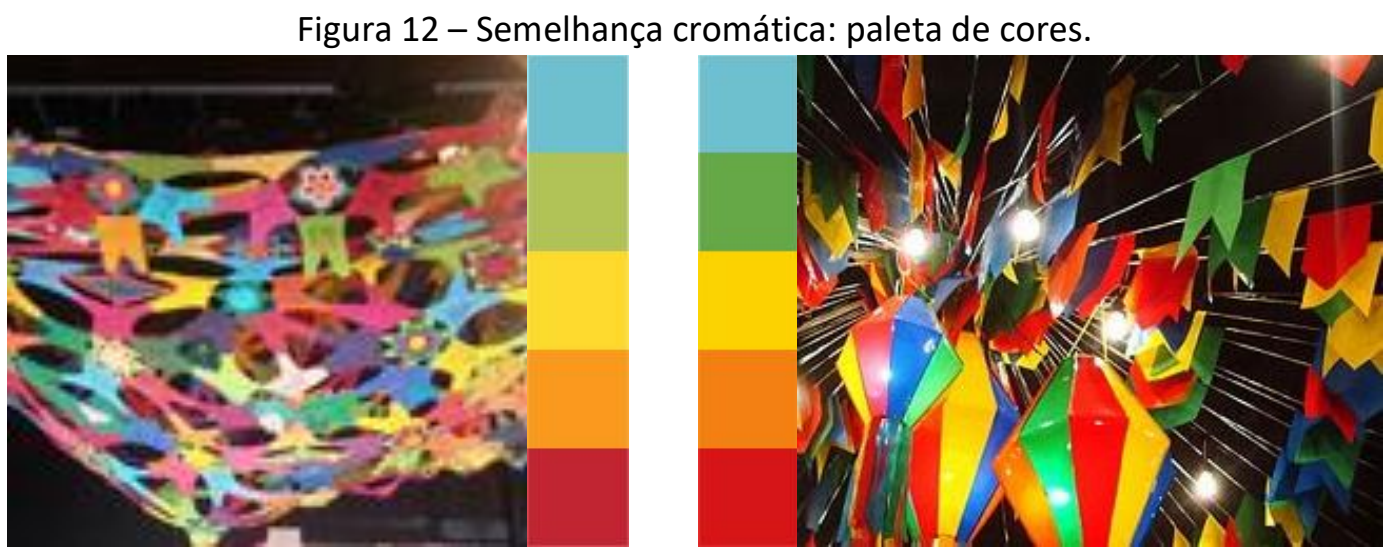

Fonte: Autoria própria (2017).

Por fim, o último signo identificado nesta edição do hall de entrada foi a luminária (Fig. 13), feita em crochê. Este elemento, por sua vez, é considerado um símbolo, tendo em vista que sua associação com o objeto representado, o candeeiro, só é assimilada por aqueles que tem algum conhecimento sobre a cultura popular nordestina. Apesar da forma mais tradicional do objeto ser a de base cônica, outros formatos também eram utilizados, como o com cúpula de vidro oval e o candeeiro a gás (Fig. 14), com cúpula de vidro arredonda.

Figura 12 - Luminária artesanal em crochê.

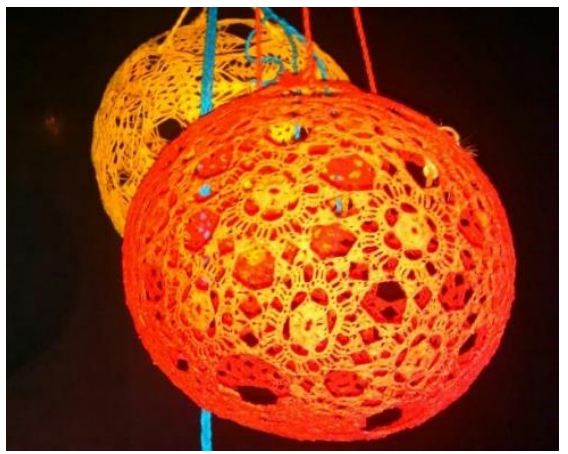

Fonte: Sílvia Cristina (2015)
Figura 13 - Candeeiro a gás.

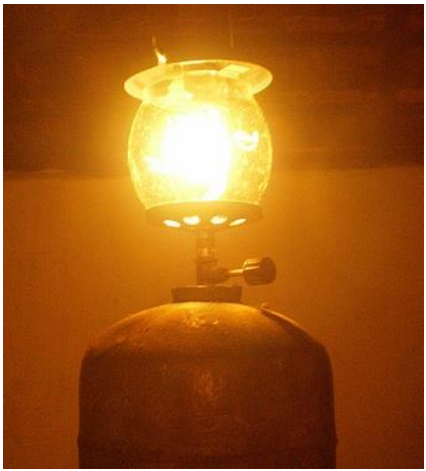

Fonte: Desmanipulador.blogspot.com.br

Deste modo, considera-se que a iluminação indireta proporcionada pela luminária decorativa traz aconchego, remetendo aos antigos candeeiros, elemento tradicional presente na grande maioria das casas do interior da Paraíba antes da chegada da rede elétrica. Para a análise deste signo, identificou-se duas categorias de referências simbólicas no produto, sendo elas: a cor simbólica e a forma simbólica.

A cor simbólica identificada no produto, nos tons de amarelo e laranja, remetem ao fogo gerado pelo lampião, fazendo uma relação simbólica entre a luz da chama do lampião e a da luminária feita em crochê. Essa referência pode, pois, ser afirmada pela comparação das paletas de cores produzidas pelo signo e por seu objeto, como ilustra a Fig. 15. 
Figura 14 - Paleta de cores: signo luminária

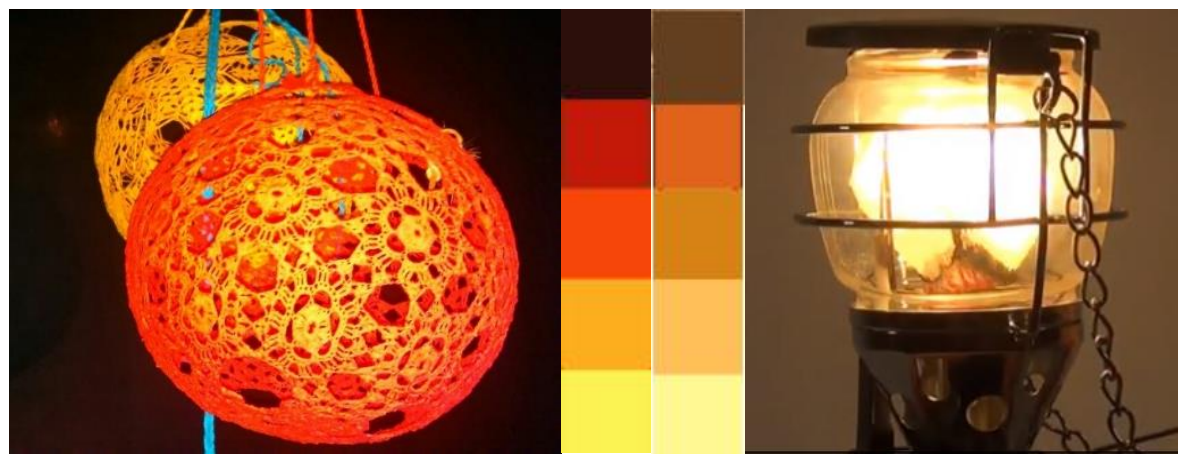

Fonte: Autoria própria (2017).

A forma simbólica presente no produto diz respeito à geometria básica que deu origem ao produto e, consequentemente, ao seu respectivo signo, o círculo. A forma redonda presente em ambos os elementos proporciona uma associação visual da forma, tornando o representante reconhecível aos que têm alguma memória relacionada à cultura paraibana, em especial às vivências em cidades interioranas. Portanto, a forma simbólica pode ser representada segundo a Fig. 16 abaixo.

Figura 15 - Forma simbólica do signo da luminária de crochê.

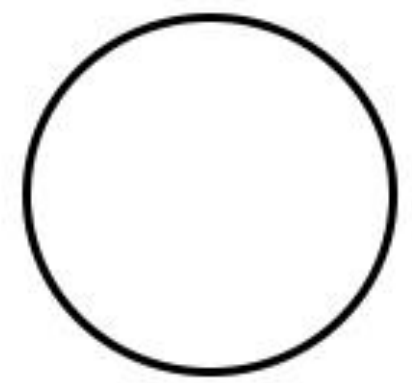

Fonte: Autoria própria (2017).

\section{Considerações Finais}

Como resultado da pesquisa realizada, constatou-se a presença de quatro elementos semióticos, ícones e símbolos, no 21 ㅇ edição do Salão de Artesanato da Paraíba, constituindo uma narrativa de identidade cultural para o espaço. Estes signos, por sua vez, representam elementos que estão relacionadas a cultura paraibana, possibilitando ao visitante do espaço fazer a associação entre o objeto mencionado e o grupo cultural ao qual pertence.

Deste modo, compreende-se que o presente estudo corroborou com tanto com a aplicação de uma forma de análise visual da identidade cultural nos ambientes quanto com a aproximação ao tema de espaços efêmeros. Estes dois conteúdos, de instalações efêmeras e percepção visual aplicada ao espaço, são tidos pelo Instituto Nacional de Estudos e Pesquisas Educacionais (INEP) como temas de referência para análise curricular dos cursos Superiores de Tecnologia em Design de Interiores no Brasil, sendo de extrema importância o aprofundamento nos referidos tópicos.

Como sugestão para estudos futuros, propõe-se realizar uma investigação acerca da criação 
de uma metodologia de análise visual. Tendo a semiótica como base, indica-se a inserção de novos critérios e categorias de associação da identidade cultural aos projetos de ambientes no geral e, especialmente, em instalações efêmeras. Além disso, os resultados obtidos na atual pesquisa podem auxiliar em outros estudos que buscam criar um método de implementação de elementos culturais em projetos de espaços construídos.

\section{Referências}

ALMEIDA, A. D. S. O design de interiores e a cenografia: relação e análise plástica do espaço habitado. Revista Científica Semana Acadêmica, Fortaleza, n. 10, nov. 2013. Disponível em: < https://semanaacademica.org.br/system/files/artigos/aplasticidadedoscenariosdacia.pdf>. Acesso em: 01 Jul. 2017.

BORBA, M. A. B. Saberes e fazeres do povo: resgate da cultura popular na Paraíba. João Pessoa: Editora Universitária UFPB, 2006.

BÜRDEK, B. E. História, teoria e prática do design de produtos. São Paulo: Edgarc Blücher, 2006.

CARNIDE, S. J. F. Arquiteturas Expositivas Efémeras. Lisboa: Universidade Técnica de Lisboa, 2012.

CURY, M. X. Exposição: concepção, montagem e avaliação. São Paulo: Annablume, 2005.

ECO, U. $O$ signo. 5 ed. Lisboa: Editora Presença, 1997.

GONÇALVES, L. R. Entre cenografias: o museu e a exposição de arte no século XX. São Paulo: Editora da Universidade de São Paulo/FAPESP, 2004.

GRILLI, S. Signos da brasilidade no design de móveis. São Paulo: SENAI-SP Editora, 2015.

MANTOVANI, A. Cenografia. São Paulo: Editora Ática S.A., 1989.

MARTINS, D. M.; MICHAIDILIS, G. M.; CÂMARA, J. J. D. O valor do artesanato: uma análise sob a perspectiva do design. Actas de Diseño, Buenos Aires, ano 12, n. 23, jul. 2017. Disponível em: <http://www.usjt.br/arq.urb/arquivos/abntnbr6023.pdf>. Acesso em: 22 ago. 2018.

MORRIS, C. W. Fundamentos da teoria dos signos. São Paulo: Ed. da Universidade de São Paulo, 1976.

NIEMEYER, L. Elementos de semiótica aplicados ao design. Rio de Janeiro: 2AB, 2016.

NISHIKAWA, G. Q. Uso do espaço efêmero aliado ao design para a experiência em benefício de marcas de moda. Curitiba: Senai, 2016.

PEIRCE, C. S. Semiótica. São Paulo: Editora Perspectiva, 1977.

ROSSI, P. A hora e a vez da arquitetura de espaços efêmeros. Revista Edificar. 24 mar. 2015. Disponível em: <https://revistaedificar.com.br/blog/19-pedro-rossi/70-a-hora-e-a-vez-daarquitetura-de-espacos-efemeros/>. Acesso em: 20 ago. 2017.

SATURNINO, D. Comunicação Visual e Expografia: um estudo de caso da exposição audiophylia. Bahia: UFRB, 2014.

SANTAELLA, L. O que é semiótica. São Paulo: Editora Brasiliense, 1983.

SOUZA, G. M. de; PEREIRA, T. J. Cultura popular. Brasília: Projeção, 2014. 